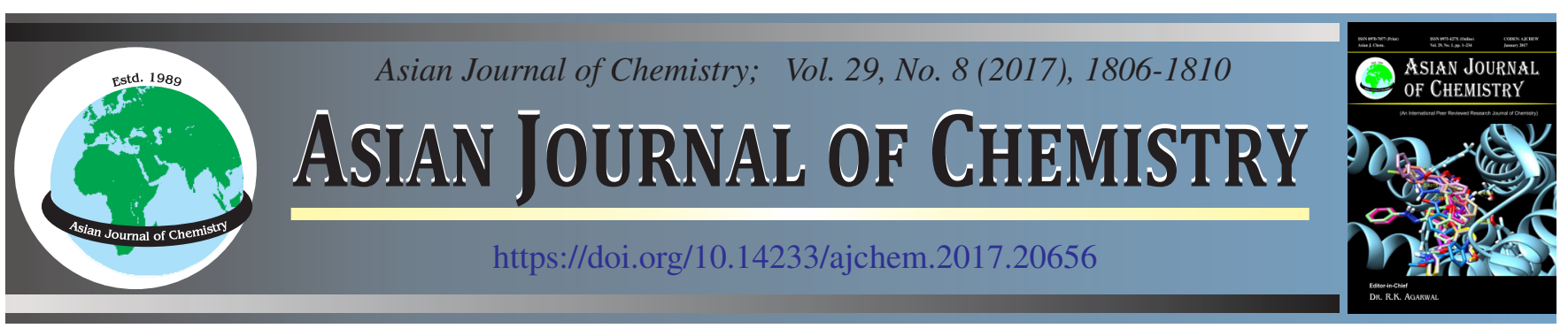

\title{
Oxidation of Some Methoxy Anilines by Tetrabutylammoniumbromochromate in Aqueous Acetic Acid Medium: A Kinetics Study
}

\author{
Shaik JABIR ${ }^{1}$, Basim H. AsghaR ${ }^{2}$ and S. SheIK Mansoor ${ }^{3, *}$
}

${ }^{1}$ Research and Development Centre, Bharathiar University, Coimbatore-641 046, India

${ }^{2}$ Department of Chemistry, Faculty of Applied Sciences, Umm Al-Qura University, P.O. Box: 9569, Makkah, Saudi Arabia

${ }^{3}$ Department of Chemistry, C. Abdul Hakeem College (Autonomous), Melvisharam-632 509, India

*Corresponding author: E-mail: smansoors2000@yahoo.co.in

Received: 18 March 2017;

Accepted: 12 April 2017;

Published online: 12 June 2017;

AJC-18446

The oxidation of aniline (A), 2,4-dimethoxy aniline (2,4-DMA), 2,6-dimethoxy aniline (2,6-DMA), 2,4,6-trimethoxy aniline (2,4,6TMA) and 3,4,5-trimethoxy aniline (3,4,5-TMA) by tetrabutylammoniumbromochromate (TBABC) have been studied in $50 \%$ acetic acid $-50 \%$ water medium in the presence of perchloric acid. The oxidation leads to the formation of the corresponding azobenzenes. The reaction is first order with respect to $[\mathrm{TBABC}],[\mathrm{S}]$ and $\left[\mathrm{H}^{+}\right]$. The reaction has been found to be catalyzed by $\mathrm{H}^{+}$ions. The reactions were studied at four different temperatures and thermodynamic parameters were calculated. The rates decreased in the order: 2,4,6-TMA > 2,6-DMA > 2,4-DMA > 3,4,5-TMA > aniline.

Keywords: Tetrabutylammoniumbromochromate, Methoxy aniline, Thermodynamic parameters, Kinetics.

\section{INTRODUCTION}

Aniline is one of the hazardous chemicals that are environmentally persistent and cannot be degraded by traditional treatment processes. It causes metheglobinemia and hemolysis; these changes can be detected by blood tests or by the colour and appearance of the blood. Children may be more vulnerable to loss of effectiveness of hemoglobin because of their relative anemia, higher metabolic rate and greater sensitivity to hypoxia compared to adults. The elderly are more vulnerable due to limited cardiovascular reserves.

Inhalation of aniline can cause respiratory tract irritation with cough, or difficulty in breathing. Persons exposed to aniline may have chronic effects due to the persistence of acutely produced damage to the brain, heart and kidneys. Wastewaters contaminated with aniline from pesticides, dyestuffs, antioxidants and pharmaceuticals can pose adverse impacts on receiving waters due to its biorefractory and highly toxic properties [1].

Chromium(VI) compounds are widely used as oxidation agents. Water-soluble potassium and sodium dichromates with strong acids were used as oxidants and in most of the cases the products were non-specific. The first attempt to make a mild reagent of substituted chromates was reported by Sarett and co-workers [2]. They used pyridine to form a salt with $\mathrm{CrO}_{3}$ in order to oxidize some steroidal alcohols. This reagent was subsequently used by various workers without analyzing the structure of the oxidant. Corey in his novel attempt to establish pyridiniumchlorochromate [3] as a versatile oxidant, revisited Sarett's reagent and discovered it to be pyridinium dichromate [4]. Significant improvements are achieved in the development of new $\mathrm{Cr}(\mathrm{VI})$ based oxidizing agents, such as pyridiniumfluorochromate [5], benzimidazoliumfluorochromate [6], tetrahexylammoniumbromochromate [6], triethylammoniumchlorochromate [7], tetraethyl ammonium bromochromate [9], tetraethylammoniumchlorochromate [10] and tetrabutylammoniumbromochromate [11].

The oxidation of aromatic amines by different oxidants have been the subject of study by various workers due to the complex behaviour of their mode of oxidation due to the formation of polymeric products, many of which find application in drug and dyestuff industries [12-16]. Aniline on oxidation gives azobenzenes which are important reagents in organic synthesis and are widely used in the synthesis of organic dyes, food additives, indicators and also in drugs [17].

The present study focuses on the study of kinetics and mechanism of oxidation of aniline, 2,6-dimethoxy aniline, 2,4dimethoxy aniline, 2,4,6-trimethoxyaniline and 3,4,5trimethoxy aniline by tetrabutylammoniumbromochromate (TBABC) in aqueous acetic acid media. Anilines (aromatic amines) are the most widespread and principal contaminants of industrial wastewaters. Better understanding of the 
mechanism of oxidation of such compounds/contaminants to harmless products is the important goal for basic research and industrial applications.

\section{EXPERIMENTAL}

Aniline, 2,6-dimethoxy aniline, 2,4-dimethoxy aniline, 2,4,6-trimethoxy aniline and 3,4,5-trimethoxy aniline were used as substrates. All the chemicals used were reagent grade products. The oxidant TBABC was prepared from chromium(VI) oxide in $\mathrm{MeCN}$ and addition of this solution to a solution of tetrabutylammonium bromide as reported in the literature [11]. Acetic acid was purified by standard method and the fraction distilling at $118^{\circ} \mathrm{C}$ was collected.

Kinetic measurements: Solutions were prepared in double-distilled water. The reaction mixtures, containing aniline, acetic acid and perchloric acid solutions, were thermally equilibrated for $1 \mathrm{~h}$ at the desired temperature. The reaction was initiated by the addition of a temperature-equilibrated TBABC solution of the requisite concentration. The rate was studied spectrophotometrically by monitoring the disappearance of [TBABC] at $364 \mathrm{~nm}$ using UV-visible spectrophotometer, Shimadzu UV-1800 model in $50 \%$ acetic acid - $50 \%$ water $(\mathrm{v} / \mathrm{v})$. All of the reactions were carried out under pseudofirst-order conditions by keeping an excess (tenfold or greater) of [Aniline] over [TBABC] i.e. [Aniline] $\gg$ [TBABC)]. The pseudo-first-order rate constants $\left(\mathrm{k}_{1}\right)$ were computed from linear plots of $\log$ [TBABC] against time up to $90 \%$ completion of the reaction. The precision of rate constant values is given in terms of $95 \%$ the confidence limit of the student's t-test [18] and the values were reproducible to within $5 \%$.

Stoichiometry and product analysis: The products in the respective oxidation of methoxyanilines were corresponding azobenzenes and this were confirmed by analysing using preparative TLC on silica gel. The stoichiometric studies showed that $1 \mathrm{~mol}$ of TBABC reacts with $1 \mathrm{~mol}$ of aniline.

\section{RESULTS AND DISCUSSION}

The reaction was studied in $50 \%$ acetic acid - $50 \%$ water medium at $303 \mathrm{~K}$, under the pseudo-first-order conditions.
The rate and other experimental data were obtained for aniline (A), 2,4-dimethoxy aniline (2,4-DMA), 2,6-dimethoxy aniline (2,6-DMA), 2,4,6-trimethoxy aniline (2,4,6-TMA) and 3,4,5trimethoxy aniline (3,4,5-TMA). The pseudo-first-order rate constants are given in Table-1. The results are summarized here.

Order of reaction: The oxidation of organic compounds with high selectivity is of extreme importance in synthetic chemistry. Reactions were carried out under pseudo first-order conditions with a known excess of [aniline] over [TBABC] at constant temperature of $303 \mathrm{~K}$ in $50 \%$ acetic acid and $50 \%$ water medium.

The values of $k_{1}$ were independent of the initial concentration of TBABC (Table-1) suggesting the reactions were of first order with respect to TBABC. The reaction was catalyzed by hydrogen ions and the order with respect to $\left[\mathrm{H}^{+}\right]$was one.

The $\mathrm{k}_{1}$ values measured at various initial concentrations of aniline for the oxidation show a linear increase (Table-1). The plot of $\log \mathrm{k}_{1}$ versus $\log$ [aniline] is excellently linear $(\mathrm{r}=$ 0.999) with unit slope, indicating that the order of the reaction with respect to [aniline] is one (Fig. 1). This is further evi-

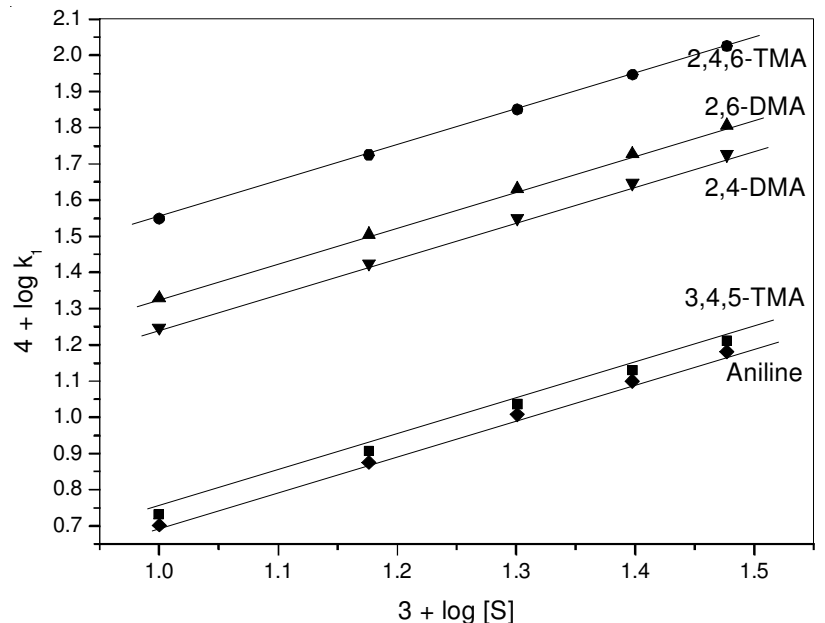

Fig. 1. The order plot of aniline (A), 2,4-dimethoxy aniline (2,4-DMA), 2,6-dimethoxy aniline (2,6-DMA), 2,4,6-trimethoxy aniline (2,4,6TMA) and 3,4,5-trimethoxy aniline (3,4,5-TMA)

\begin{tabular}{|c|c|c|c|c|c|c|c|}
\hline \multirow{3}{*}{$\begin{array}{l}10^{3}[\mathrm{TBABC}] \\
\left(\mathrm{mol} \mathrm{dm}^{-3}\right)\end{array}$} & \multicolumn{6}{|c|}{$\begin{array}{c}\text { TABLE-1 } \\
\text { EFFECT OF VARIATION OF [S], [TBABC] AND [H+ }{ }^{+} \text {ON THE RATE OF REACTION AT } 303 \text { K }{ }^{\mathrm{a}}\end{array}$} & \\
\hline & \multirow{2}{*}{$\begin{array}{c}10^{2}[\mathrm{~S}] \\
\left(\mathrm{mol} \mathrm{dm} \mathrm{dm}^{-3}\right)\end{array}$} & \multirow{2}{*}{$\begin{array}{c}{\left[\mathrm{H}^{+}\right]} \\
\left(\mathrm{mol} \mathrm{dm} \mathrm{dm}^{-3}\right)\end{array}$} & \multicolumn{5}{|c|}{$10^{4} \mathrm{k}_{1}\left(\mathrm{~s}^{-1}\right)^{\mathrm{b}}$} \\
\hline & & & $\mathrm{H}$ & 2,4-DMA & 2,6-DMA & 2,4,6-TMA & 3,4,5-TMA \\
\hline 0.6 & 2.0 & 0.16 & 10.08 & 35.50 & 42.68 & 70.80 & 10.80 \\
\hline 1.0 & 2.0 & 0.16 & 10.16 & 35.56 & 42.76 & 70.84 & 10.88 \\
\hline 1.6 & 2.0 & 0.16 & 10.18 & 35.58 & 42.70 & 70.76 & 10.94 \\
\hline 2.0 & 2.0 & 0.16 & 10.06 & 35.60 & 42.74 & 70.72 & 10.86 \\
\hline 2.6 & 2.0 & 0.16 & 10.20 & 35.54 & 42.72 & 70.86 & 10.82 \\
\hline 1.0 & 1.2 & 0.16 & 5.04 & 17.68 & 21.30 & 33.30 & 5.40 \\
\hline 1.0 & 1.6 & 0.16 & 7.50 & 26.58 & 32.00 & 53.06 & 8.08 \\
\hline 1.0 & 2.4 & 0.16 & 12.60 & 44.40 & 53.36 & 88.48 & 13.52 \\
\hline 1.0 & 2.8 & 0.16 & 15.16 & 53.26 & 64.08 & 106.16 & 16.24 \\
\hline 1.0 & 2.0 & 0.10 & 6.40 & 22.22 & 26.80 & 44.34 & 6.82 \\
\hline 1.0 & 2.0 & 0.20 & 12.60 & 44.52 & 53.52 & 88.64 & 13.56 \\
\hline 1.0 & 2.0 & 0.26 & 16.48 & 57.82 & 69.56 & 115.18 & 17.58 \\
\hline 1.0 & 2.0 & 0.30 & 19.00 & 66.72 & 80.26 & 132.88 & 20.32 \\
\hline 1.0 & 2.0 & 0.16 & $10.04^{\mathrm{c}}$ & $35.38^{c}$ & $42.56^{c}$ & $70.56^{\mathrm{c}}$ & $10.72^{c}$ \\
\hline 1.0 & 2.0 & 0.16 & $7.98^{\mathrm{d}}$ & $28.42^{\mathrm{d}}$ & $35.24^{\mathrm{d}}$ & $56.64^{d}$ & $8.32^{\mathrm{d}}$ \\
\hline
\end{tabular}

${ }^{\mathrm{a}}$ As determined by spectrophotometrically following the disappearance of $\mathrm{Cr}(\mathrm{VI})$ at $364 \mathrm{~nm}$; ${ }^{\mathrm{b}}$ Estimated from pseudo first order plots; ${ }^{\mathrm{c}}$ In the presence of $0.001 \mathrm{~mol} \mathrm{dm}^{-3}$ acrylonitrile; ${ }^{\mathrm{d}} \mathrm{In}$ the presence of $0.003 \mathrm{~mol} \mathrm{dm}{ }^{-3} \mathrm{Mn}(\mathrm{II})$; Solvent composition $=50 \% \mathrm{AcOH}-50 \% \mathrm{H}_{2} \mathrm{O}(\mathrm{v} / \mathrm{v})$ 
denced by the excellent linearity observed in the plot of $\mathrm{k}_{1}$ versus [aniline], which passes through origin (Fig. 2).

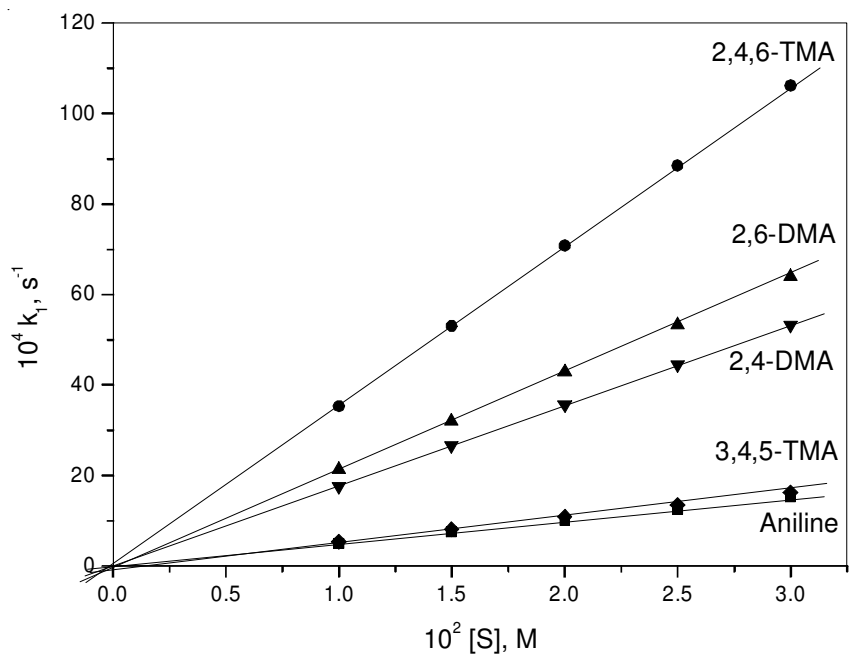

Fig. 2. Direct plot of aniline (A), 2,4-dimethoxy aniline (2,4-DMA), 2,6dimethoxy aniline (2,6-DMA), 2,4,6-trimethoxy aniline (2,4,6TMA) and 3,4,5-trimethoxy aniline (3,4,5-TMA)

Effect of acrylonitrile and $\mathrm{MnSO}_{4}$ : The involvement of free-radical intermediates in the present study can be excluded, as the rate constant is not affected by the addition of acrylonitrile. The addition of $\mathrm{Mn}$ (II) indicating the involvement of a two-electron reduction of $\mathrm{Cr}(\mathrm{VI})$ to $\mathrm{Cr}(\mathrm{IV})$ (Table-1).

Effect of solvent polarity on reaction rate: In binary mixtures of acetic acid and water as solvent, the rate of the reaction increases remarkably with an increase in the proportion of acetic acid in the medium (Table-2). The concentration of acetic acid varied from 30 to $70 \%$ and the rate were measured. When the acetic acid content is increased, the acidity of the medium increases while the dielectric constant of the medium decreases. These two effects cause the rate of the oxidation to increase remarkably. A plot of $\log \mathrm{k}_{1}$ versus 1/D has been given in Fig. 3. The linear plot obtained indicates that the involvement of cationdipole type of interaction in the rate determining step [19].

Structure reactivity correlation: The effect of structure on reactivity indicates that, the reactivity decreases in the order: 2,4,6-TMA > 2,6-DMA > 2,4-DMA > 3,4,5-TMA > aniline for the substituents. Methoxy group at ortho $\left[\sigma\left(\mathrm{OCH}_{3}\right)=\right.$ - 0.39] and para $\left[\sigma\left(\mathrm{OCH}_{3}\right)=-0.27\right]$ to aniline enhances the rate while at meta $\left[\sigma\left(\mathrm{OCH}_{3}\right)=+0.12\right]$ reduces the rate.

Thus for 2,4-DMA $\left[\sigma\left(\mathrm{OCH}_{3}\right)=-0.66\right]<2,6$-DMA $\left[\sigma\left(\mathrm{OCH}_{3}\right)=-0.78\right]$ and also for 3,4,5 - TMA $\left[\sigma\left(\mathrm{OCH}_{3}\right)=\right.$ $-0.03]<2,4,6$ - TMA $\left[\sigma\left(\mathrm{OCH}_{3}\right)=-1.05\right]$.

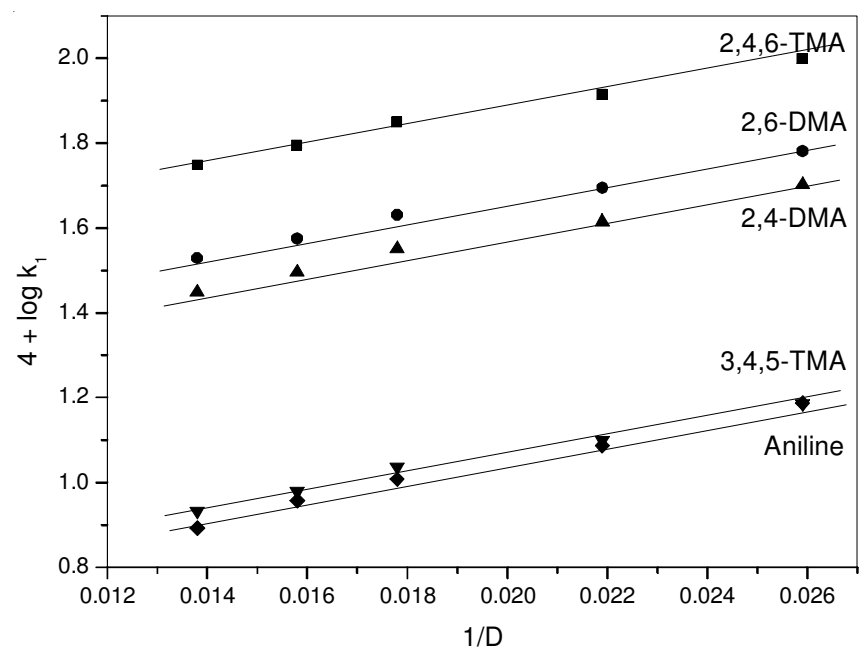

Fig. 3. Plot of $1 / \mathrm{D}$ against $\log \mathrm{k}_{1}$ showing effect of solvent polarity for the oxidation of aniline (A), 2,4-dimethoxy aniline (2,4-DMA), 2,6dimethoxy aniline (2,6-DMA), 2,4,6-trimethoxy aniline $(2,4,6$ TMA) and 3,4,5-trimethoxy aniline (3,4,5-TMA) by TBABC

Activation parameters: The first-order rate constants for the oxidation of aniline, 2,6-DMA, 2,4-DMA, 2,4,6-TMA and 3,4,5-TMA with TBABC at four different temperatures were collected in Table-3. A linear Arrhenius plot of $\log \mathrm{k}_{2}$ versus $1 / \mathrm{T}$ is obtained. From the Eyring relationship, various thermodynamic parameters were calculated and the values were presented in Table-4.

TABLE-3

PSEUDO-FIRST ORDER RATE CONSTANTSFOR THE OXIDATION OFANILINE, 2,4-DMA, 2,6-DMA, 2,4,6-TMA AND 3,4,5-TMA BY TBABC AT VARIOUS TEMPERATURES IN AQUEOUS ACETIC ACID MEDIUM

\begin{tabular}{lcccc}
\hline \multirow{2}{*}{ Substrate } & \multicolumn{4}{c}{$10^{4} \mathrm{k}_{1}\left(\mathrm{~s}^{-1}\right)$} \\
\cline { 2 - 5 } & $298 \mathrm{~K}$ & $303 \mathrm{~K}$ & $308 \mathrm{~K}$ & $313 \mathrm{~K}$ \\
\hline $\mathrm{H}$ & 7.08 & 10.16 & 14.50 & 20.40 \\
2,4-DMA & 26.92 & 35.56 & 46.88 & 61.92 \\
2,6-DMA & 32.88 & 42.76 & 55.56 & 72.24 \\
2,4,6-TMA & 55.30 & 70.84 & 90.52 & 115.88 \\
3,4,5-TMA & 7.78 & 10.88 & 15.24 & 21.32 \\
\hline
\end{tabular}

$10^{2}[\mathrm{~S}]=2.0 \mathrm{~mol} \mathrm{dm}^{-3} ; 10^{3}[\mathrm{TBABC}]=1.0 \mathrm{~mol} \mathrm{dm}^{-3} ; 10\left[\mathrm{H}^{+}\right]=1.6 \mathrm{~mol}$ $\mathrm{dm}^{-3}$; Solvent composition $=50 \% \mathrm{AcOH}-50 \% \mathrm{H}_{2} \mathrm{O}(\mathrm{v} / \mathrm{v})$

Isokinetic temperature: An Exner's plot [20] between $\log \mathrm{k}_{2}$ at $298 \mathrm{~K}$ and at $303 \mathrm{~K}$ was linear (Fig. 4). The value of isokinetic temperature evaluated from the Exner's plot is 448 $\mathrm{K}$. From the linear isokinetic relationship, it is implied that same mechanism is applicable for the oxidation of all the methoxy anilines [21].

TABLE-2

EFFECT OF VARYING SOLVENT POLARITY ON THE RATE OF REACTION OF ANILINE, 2,4-DMA, 2,6-DMA, 2,4,6-TMA AND 3,4,5-TMA BY TBABC AT $303 \mathrm{~K}$

\begin{tabular}{|c|c|c|c|c|c|c|}
\hline \multirow{2}{*}{$\begin{array}{c}\% \mathrm{AcOH}-\mathrm{H}_{2} \mathrm{O} \\
(\mathrm{v} / \mathrm{v})\end{array}$} & \multirow{2}{*}{$\begin{array}{l}\text { Dielectric } \\
\text { constant }\end{array}$} & \multicolumn{5}{|c|}{$10^{4} \mathrm{k}_{1}\left(\mathrm{~s}^{-1}\right)$} \\
\hline & & $\mathrm{H}$ & 2,4-DMA & 2,6-DMA & 2,4,6-TMA & 3,4,5-TMA \\
\hline $30-70$ & 72.0 & 7.80 & 28.16 & 33.86 & 56.10 & 8.56 \\
\hline $40-60$ & 63.3 & 9.06 & 31.28 & 37.62 & 62.34 & 9.52 \\
\hline $50-50$ & 56.0 & 10.16 & 35.56 & 42.76 & 70.84 & 10.88 \\
\hline $60-40$ & 45.5 & 12.20 & 41.20 & 49.60 & 82.12 & 12.56 \\
\hline $70-30$ & 38.5 & 15.40 & 50.32 & 60.50 & 100.22 & 15.32 \\
\hline
\end{tabular}

$10^{2}[\mathrm{~S}]=2.0 \mathrm{~mol} \mathrm{dm}^{-3} ; 10^{3}[\mathrm{TBABC}]=1.0 \mathrm{~mol} \mathrm{dm}^{-3} ; 10\left[\mathrm{H}^{+}\right]=1.6 \mathrm{~mol} \mathrm{dm}^{-3}$ 


\begin{tabular}{|c|c|c|c|c|c|c|c|c|}
\hline \multirow{3}{*}{ Substrate } & \multicolumn{8}{|c|}{$\begin{array}{l}\text { TABLE-4 } \\
\text { ACTIVATION PARAMETERS AND SECOND ORDER RATE CONSTANTS FOR THE OXIDATION OFANILINE, } \\
\text { 2,4-DMA, 2,6-DMA, 2,4,6-TMA AND 3,4,5-TMA BY TBABC IN AQUEOUS ACETIC ACID MEDIUM }\end{array}$} \\
\hline & \multicolumn{4}{|c|}{$10^{2} \mathrm{k}_{2}\left(\mathrm{dm}^{3} \mathrm{~mol}^{-1} \mathrm{~s}^{-1}\right)$} & \multirow{2}{*}{$\begin{array}{c}\mathrm{E}_{\mathrm{a}} \\
\left(\mathrm{kJ} \mathrm{mol}^{-1}\right)\end{array}$} & \multirow{2}{*}{$\begin{array}{c}\Delta \mathrm{H}^{\#} \\
\left(\mathrm{~kJ} \mathrm{~mol}^{-1}\right)\end{array}$} & \multirow{2}{*}{$\begin{array}{c}\Delta \mathrm{S}^{\#} \\
\left(\mathrm{JK}^{-1} \mathrm{~mol}\right)\end{array}$} & \multirow{2}{*}{$\begin{array}{c}\Delta \mathrm{G}^{\#}\left(\mathrm{~kJ} \mathrm{~mol}^{-1}\right) \\
\text { at } 303 \mathrm{~K}\end{array}$} \\
\hline & $298 \mathrm{~K}$ & $303 \mathrm{~K}$ & $308 \mathrm{~K}$ & $313 \mathrm{~K}$ & & & & \\
\hline $\mathrm{H}$ & 3.54 & 5.08 & 7.25 & 10.20 & 54.94 & $52.30 \pm 0.2$ & $96.86 \pm 0.6$ & $81.63 \pm 0.4$ \\
\hline 2,4-DMA & 13.46 & 17.78 & 23.44 & 30.96 & 43.26 & $40.58 \pm 0.6$ & $125.19 \pm 1.8$ & $78.51 \pm 1.2$ \\
\hline 2,6-DMA & 16.44 & 21.38 & 27.78 & 36.12 & 40.78 & $38.29 \pm 0.4$ & $131.51 \pm 1.2$ & $78.14 \pm 0.8$ \\
\hline 2,4,6-TMA & 27.65 & 35.42 & 45.26 & 57.94 & 38.29 & $35.80 \pm 0.2$ & $135.53 \pm 0.6$ & $76.86 \pm 0.4$ \\
\hline 3,4,5-DMA & 3.89 & 5.44 & 7.62 & 10.66 & 52.26 & $49.78 \pm 0.3$ & $104.90 \pm 0.9$ & $81.56 \pm 0.6$ \\
\hline
\end{tabular}

$10^{2}[\mathrm{~S}]=2.0 \mathrm{~mol} \mathrm{dm}^{-3} ; 10^{3}[\mathrm{TBABC}]=1.0 \mathrm{~mol} \mathrm{dm}^{-3} ; 10\left[\mathrm{H}^{+}\right]=1.6 \mathrm{~mol} \mathrm{dm}^{-3} ;$ Solvent composition $=50 \%$ AcOH $-50 \% \mathrm{H}_{2} \mathrm{O}(\mathrm{v} / \mathrm{v})$

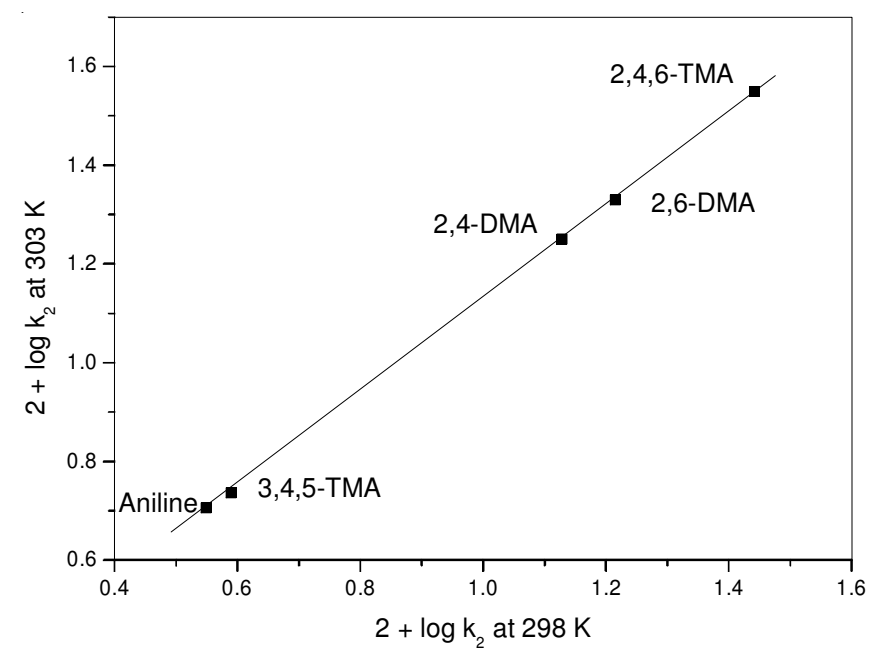

Fig. 4. Exner's plot for the oxidation of aniline (A), 2,4-dimethoxy aniline (2,4-DMA), 2,6-dimethoxy aniline (2,6-DMA), 2,4,6-trimethoxy aniline (2,4,6-TMA) and 3,4,5-trimethoxy aniline (3,4,5-TMA)by TBABC between $2+\log \mathrm{k}_{2}(303 \mathrm{~K})$ and $2+\log \mathrm{k}_{2}(298 \mathrm{~K})$
Mechanism: The reaction rate increases linearly with the increase in $\left[\mathrm{H}^{+}\right]$ion and hence protonated TBABC is formed. The rate enhancement is observed in the present study with increase in the acetic acid content of the solvent medium. The corresponding methoxyazobenzenes were obtained as products for the oxidation of methoxy anilines. The involvement of freeradical intermediates in the present study can be excluded, as the rate constant is not affected by the addition of acrylonitrile. The addition of $\mathrm{Mn}$ (II) in the form of $\mathrm{MnSO}_{4}$, retards the rate of oxidation, indicating the involvement of a two-electron reduction of $\mathrm{Cr}(\mathrm{VI})$ to $\mathrm{Cr}(\mathrm{IV})$.A linear plot of $\log \mathrm{k}_{1}$ versus $1 / \mathrm{D}$ with positive slope indicates that the involvement of a cation-dipole type of interaction in the rate determining step. The product formation is in accordance with the literature report [22]. The sequence of the oxidation is similar to that reported in the literature [23]. The negative entropy of activation in conjunction with other kinetic observations supports the mechanism (Scheme-I).

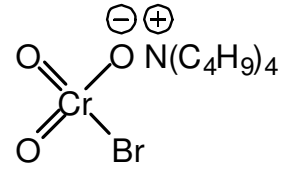

TBABC
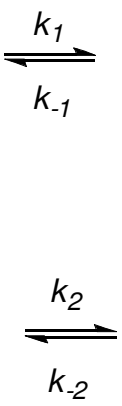

$\Theta \oplus$

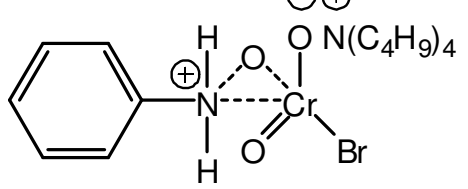<smiles>ONc1ccccc1</smiles>

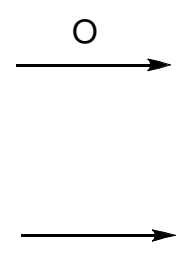<smiles></smiles>

$\mathrm{TBABCH}^{+}$

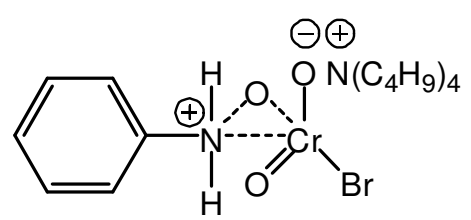<smiles></smiles><smiles>O=[N+]c1ccccc1</smiles><smiles></smiles>

Azobenzene

Scheme-I: Mechanism of oxidation of aniline by tetrabutylammoniumbromochromate (TBABC) 


\section{Conclusion}

In this work, the detailed kinetics of oxidation of aniline (A), 2,4-dimethoxy aniline (2,4-DMA), 2,6-dimethoxy aniline (2,6-DMA), 2,4,6-trimethoxy aniline (2,4,6-TMA) and 3,4,5trimethoxy aniline (3,4,5-TMA) in acetic acid-water medium has been studied by spectrophotometrically at $303 \mathrm{~K}$ using TBABC as an oxidant. Methoxy group at ortho $\left[\sigma\left(\mathrm{OCH}_{3}\right)=\right.$ - 0.39] and para $\left[\sigma\left(\mathrm{OCH}_{3}\right)=-0.27\right]$ to aniline enhances the rate while at meta $\left[\sigma\left(\mathrm{OCH}_{3}\right)=+0.12\right]$ reduces the rate. Higher rate is observed for 2,4,6-trimethoxyaniline and lower rate for aniline.

\section{ACKNOWLEDGEMENTS}

One of the authors, Shaik Jabir expresses his gratitude to the Research and Development Centre, Bharathiar University, Coimbatore, India for the facilities and support. Another author S.S. Mansoor is thankful to the Management of C. Abdul Hakeem College (Autonomous), Melvisharam, India for the support.

\section{REFERENCES}

1. N. Boonrattanakij, M.C. Lu and J. Anotai, J. Hazard. Mater., 172, 952 (2009); https://doi.org/10.1016/j.jhazmat.2009.07.079.

2. G.I. Poos, G.E. Arth, R.E. Beyler and L.H. Sarett, J. Am. Chem. Soc., 75, 422 (1953);

https://doi.org/10.1021/ja01098a049.

3. E.J. Corey and J.W. Suggs, Tetrahedron Lett., 16, 2647 (1975); https://doi.org/10.1016/S0040-4039(00)75204-X

4. E.J. Corey and G. Schmidt, Tetrahedron Lett., 20, 399 (1979); https://doi.org/10.1016/S0040-4039(01)93515-4.

5. S.Z. Ahmed, S.S. Shafi and S.S. Mansoor, Asian J. Chem., 25, 8245 (2013);

https://doi.org/10.14233/ajchem.2013.13559.
6. S.S. Mansoor, Asian J. Chem., 22, 7591 (2010).

7. S.S. Mansoor and B.H. Asghar, J. Indian Chem. Soc., 90, 1395 (2013).

8. S. Ghammamy and S. Dastpeyman, J. Chin. Chem. Soc. (Taipei), 55, 229 (2008); https://doi.org/10.1002/jccs.200800034

9. S.S. Mansoor and S.S. Shafi, Z. Phys. Chem., 225, 249 (2011); https://doi.org/10.1524/zpch.2011.0044.

10. P. Swami, D. Yajurvedi, P. Mishra and P.K. Sharma, Int. J. Chem. Kinet., 42, 50 (2010); https://doi.org/10.1002/kin.20466.

11. G. Ghammamy, K. Mehrani, H. Afrand and M. Hajighahrammani, Afr. J. Pure Appl. Chem., 1, 8 (2007).

12. S.B. Patwari, S.V. Khansole and Y.B. Vibhute, J. Iran. Chem. Soc, 6, 399 (2009); https://doi.org/10.1007/BF03245850.

13. V.K. Gupta, React. Catal. Lett., 27, 207 (1985); https://doi.org/10.1007/BF02064488.

14. S.S. Mansoor and S.S. Shafi, Arab. J. Chem., 7, 171 (2014); https://doi.org/10.1016/j.arabjc.2010.10.020.

15. D.S. Bhuvaneswari and K.P. Elango, Int. J. Chem. Kinet., 38, 657 (2006); https://doi.org/10.1002/kin.20199.

16. D.S. Bhuvaneshwari and K.P. Elango, Z. Naturforsch., 60b, 1105 (2005).

17. C.A.H. Aguilar, J. Narayanan, N. Singh and P. Thangarasu, J. Phys. Org. Chem., 27, 440 (2014); https://doi.org/10.1002/poc.3281.

18. C. Srinivasan, S. Rajagopal and A. Chellamani, J. Chem. Soc. Perkin Trans. II, 1839 (1990); https://doi.org/10.1039/p29900001839.

19. E.S. Amis, Solvent Effects on Reaction Rates and Mechanisms, Academic Press, New York, p. 42 (1967)

20. O. Exner, J.R. Streitwiser and R.W. Talt, Progress in Physical Organic Chemistry, John Wiley, New York, p. 41 (1973).

21. J.F. Leffler and E. Grunwald, Rates and Equilibrium of Organic Reactions, Wiley, New York (1963).

22. T. Alam, H. Tarannum, S.R. Ali and Kamaluddin, J. Colloid Interface Sci., 245, 251 (2002); https://doi.org/10.1006/jcis.2001.7968.

23. S. Jabir, B.H. Asghar and S.S. Mansoor, Orient. J. Chem., 33, 288 (2017); https://doi.org/10.13005/ojc/330134. 